\title{
Development of indicators for quality assurance in public health medicine
}

\author{
Nicholas H Johnston, K M Venkat Narayan, Danny A Ruta
}

\begin{abstract}
Objectives - To develop structure, process, and outcome indicators within a quality rating index for audit of public health medicine.

Design - Development of an audit matrix and indicator of quality through a series of group discussions with public health physicians, from which self administered weighted questionnaires were constructed by a modified Delphi technique.
\end{abstract}

Setting - Five Scottish health boards.

Subjects - Public health physicians in the five health boards.

Main measures - Indicators of quality and a quality rating index for seven selected service categories for each of seven agreed roles of public health medicine: assessment of health and health care needs in information services, input into managerial decision making in health promotion, fostering multisectoral collaboration in environmental health services, health service research and evaluation for child services, lead responsibility for the development and/or running of screening services, and public health medicine training and staff development in communicable disease.

Results - Indicators in the form of questionnaires were developed for each topic. Three types of indicator emerged: "global," "restricted," and "specific." A quality rating index for each topic was developed on the basis of the questionnaire scores. Piloting of indicators showed that they are potentially generalisable; evaluation of the system is under way across all health boards in Scotland.

Conclusion - Measurable indicators of quality for public health medicine can be developed.

(Quality in Health Care 1992;1:225-230)

\section{Introduction}

Medical audit has been defined as the "systematic and critical analysis of the quality of medical care." Its aim is to contribute to improving the health of the population by specifically examining and improving the quality of doctors' work. ${ }^{2}$ Quality assurance is a more general term, most commonly applied to the managerial orientation of an organisation or activity, in which routine practice incorporates the assessment and improvement of that practice. In the health care environment such improvement can involve the efforts of managers, doctors, nurses, or other medical and support staff; quality assurance must therefore be the responsibility of all members of staff and be active "throughout the whole, total organisation." 3

Public health medicine has been described as "an organised response to the protection and promotion of human health," in which the responsibilities of the specialty centre around disease prevention, health promotion, and health care deployment at population level. ${ }^{5}$ Long term goals are strategically tackled by multidisciplinary consultation and action, frequently encouraging public participation.

Consequently, quality assurance within public health medicine presents inherent difficulties. The traditional audit model of structure, process, and outcome analysis as outlined by Donabedian ${ }^{6}$ does not readily conform to the activities and responsibilities of the specialty. With outcomes that can be long term, involving several medical and nonmedical agents, measurement of the quality of activity in public health medicine is difficult. The principles of audit and quality assurance remain relevant to the discipline, but in order to assess strategically and then assure quality through structure, process, and outcome indicators, new tools are required. ${ }^{7}$ An index approach has been acknowledged as often the only means to tackle the kind of problem that requires "measures or techniques that do not yet exist." 8 We describe the development of measurable indicators for the audit of public health medicine.

\section{Methods}

DEVELOPMENT OF AUDIT MATRIX

We devised a conceptual model to enable the entire sphere of activities of public health medicine to be mapped out in diagrammatic form. This model consisted of a matrix in which the $y$ axis described the roles and responsibilities of public health medicine, as outlined in the Acheson report, ${ }^{5}$ and the $\mathrm{x}$ axis the various services provided by a health authority or board to which the roles and responsibilities of public health medicine may be applied. The matrix was revised through consultation with 40 public health physicians from five Scottish health boards, culminating in a consensus meeting, which led to the formulation of the final content, structure, and wording of the matrix framework (box 1). This stage of the project will be described in detail elsewhere.
Mr Johnston

Accepted for publication

12 October 1992 


\begin{tabular}{|c|c|c|c|c|c|c|c|}
\hline \multicolumn{8}{|c|}{ Service cut } \\
\hline $\begin{array}{l}\text { Responsibilities of public health } \\
\text { medicine }\end{array}$ & $\begin{array}{c}\text { A } \\
\text { Board } \\
\text { health } \\
\text { policy and } \\
\text { manage- } \\
\text { ment }\end{array}$ & $\begin{array}{c}\text { B } \\
\text { Information } \\
\text { services }\end{array}$ & $\begin{array}{c}\text { C } \\
\text { Health } \\
\text { promotion }\end{array}$ & $\begin{array}{l}\text { D } \\
\text { Screening } \\
\text { services }\end{array}$ & $\begin{array}{c}\mathbf{E} \\
\text { Communi- } \\
\text { cable } \\
\text { diseasc }\end{array}$ & $\begin{array}{c}\mathbf{F} \\
\text { Environ- } \\
\text { mental } \\
\text { health } \\
\text { services }\end{array}$ & \\
\hline \multicolumn{8}{|l|}{$\begin{array}{l}1 \text { Assessement of health and health care } \\
\text { needs }\end{array}$} \\
\hline \multicolumn{7}{|l|}{2 Input into managerial decision making } & \\
\hline \multicolumn{7}{|l|}{3 Fostering multisectoral collaboration } & \\
\hline \multicolumn{8}{|l|}{$\begin{array}{l}4 \text { Facilitating the development of quality } \\
\text { assurance including clinical audit }\end{array}$} \\
\hline \multicolumn{7}{|l|}{5 Health service research and evaluation } & \\
\hline \multicolumn{8}{|l|}{$\begin{array}{l}6 \text { Lead responsibility for the development } \\
\text { and/or running of the service* }\end{array}$} \\
\hline $\begin{array}{l}7 \text { Public health medicine training and staff } \\
\text { development }\end{array}$ & & & & & & & \\
\hline
\end{tabular}

Box 1 Audit matrix framework

CHOICE OF TOPICS

The public health physicians within the five boards were asked to identify "cells" for which audit indicators could be developed as part of a pilot study. Seven cells were selected to represent each of the seven agreed roles and responsibilities of public health medicine. The service categories represented were diverse, including information services, health promotion, and screening services. Each health board developed one set of indicators, with the exception of Grampian Health Board, which undertook responsibility for three cells (box 2).

DEVELOPMENT OF INDICATORS

After an extensive literature review of audit, quality assurance, public health medicine, and aspects of the service categories for each cell preliminary meetings were held at each board; they typically comprised four or five local public health physicians and two members of the research team. The meetings were semistructured brainstorming sessions chaired by the researchers, lasting for around one and a half hours, and designed to produce a preliminary set of structure, process, and outcome indicators of quality of practice within public health medicine for one cell of the matrix. The objective and quantifiable criteria of quality of practice arising from these meetings were used to construct self administered questionnaires, each board developing a questionnaire for its own cell. These were returned to each local group of public health physicians four to six weeks later. During a second round of meetings, which lasted some two to two and a half hours, the questionnaires were assessed for face and content validity before reaching their final form.

\section{SCORING SYSTEM}

Without a quantifiable measure of quality the usefulness of the indicator method as a means of comparative audit is diminished. In order to fulfil the aim of developing an audit framework that yields quantifiable results we developed a scoring system for the audit questionnaires, in which each question and response was weighted according to its relative

\begin{tabular}{|c|c|c|}
\hline Cell & Health board & Description \\
\hline B1 & Forth Valley & $\begin{array}{l}\text { Assessment of health and } \\
\text { health care needs in } \\
\text { information services }\end{array}$ \\
\hline $\mathrm{C} 2$ & Borders & $\begin{array}{l}\text { Input into managerial } \\
\text { decision making in health } \\
\text { promotion }\end{array}$ \\
\hline F3 & Highland & $\begin{array}{l}\text { Fostering multisectoral } \\
\text { collaboration in } \\
\text { environmental health } \\
\text { services }\end{array}$ \\
\hline 14 & Grampian & $\begin{array}{l}\text { Facilitating the } \\
\text { development of quality } \\
\text { assurance including } \\
\text { clinical audit for } \\
\text { outpatients services }\end{array}$ \\
\hline N5 & Grampian & $\begin{array}{l}\text { Health service research } \\
\text { and evaluation for child } \\
\text { services }\end{array}$ \\
\hline D6 & $\begin{array}{l}\text { Argyll and } \\
\text { Clyde }\end{array}$ & $\begin{array}{l}\text { Lead responsibility for the } \\
\text { development and/or } \\
\text { running of screening } \\
\text { services }\end{array}$ \\
\hline $\mathrm{E} 7$ & Grampian & $\begin{array}{l}\text { Public health medicine } \\
\text { training and staff } \\
\text { development in } \\
\text { communicable disease }\end{array}$ \\
\hline
\end{tabular}

Box 2 Seven cells identified for development of audit indicators

importance as measures of quality. A consensus was required if the scoring system was to avoid individual biases. The scoring system was based on a Delphi method, ${ }^{6}$ in which individual physicians in each board ascribed scores or weights to each question and possible response in their cell, sending their recommendations to the researchers. Each physician scored the questionnaire independently, allocating a weight of one to the question considered to make the least contribution to the measurement of quality. This question was used as a baseline, and all the other questions were weighted in proportion. The individual weightings were then converted to percentages, to enable direct comparisons. Thus if a total of 34 points had been allocated to the indicators for structure by an individual physician the scores for those questions and responses relating to structure were recalculated as a percentage of 34 , the 


\begin{tabular}{|c|c|c|c|c|c|c|c|}
\hline $\begin{array}{r}\text { I } \\
\text { services }\end{array}$ & $\mathbf{J}$ & $\mathbf{K}$ & $\begin{array}{c}\mathbf{L} \\
\text { Care grou }\end{array}$ & $\underset{\text { orogrammes }}{\mathbf{M}}$ & $\mathbf{N}$ & $\mathbf{O}$ & $\underset{\text { Major }}{\mathbf{P}}$ \\
\hline Outpatients & Elderly & Mentally ill & $\begin{array}{c}\text { Mentally } \\
\text { handi- } \\
\text { capped }\end{array}$ & $\begin{array}{c}\text { Physically } \\
\text { handi- } \\
\text { capped }\end{array}$ & Children & $\begin{array}{l}\text { Maternal } \\
\text { hcalth and } \\
\text { family } \\
\text { planning }\end{array}$ & $\begin{array}{l}\text { incident } \\
\text { planning }\end{array}$ \\
\hline & & & & & & & \\
\hline & & & & & & & \\
\hline & & & & & & & \\
\hline & & & & & & & \\
\hline & & & & & & & \\
\hline ! & & & & & & & \\
\hline & & & & & & & \\
\hline
\end{tabular}

maximum available. A similar method was used for the process and outcome scores. Individual physicians' scores were aggregated, and mean scores and ranges were fed back to the contributors at local board level, who had the opportunity to alter the scores to best reflect their importance in terms of quality measurement. Final scores and weightings were ascribed after this second round of consultation, leading to the development of a weighted questionnaire in which the three sections - structure, process, and outcome each totalled 100 points. Measuring audited practice against the 100 maximum points generates a "quality rating index," ranging from 0 to 100 points, from lowest to highest quality.

"Not appropriate" responses, an option provided for indicator questions that might not be relevant to a given department in certain circumstances, were not scored. Instead, when such a response was selected the score for that section (structure, process, or outcome) was adjusted by removing the score for that question from the denominator of the rating calculation before calculating the percentage rating.

\section{GENERALISABII ITTY}

To assess the extent to which this audit method can provide generalisable quality measures the questionnaires were piloted after this stage. Each indicator questionnaire developed by one health board was assigned randomly to one of the four other boards and used in a departmental audit. A member of the research team was present at each pilot session, and suggested improvements were recorded and used to reformulate indicators as necessary.

\section{Results}

CHOICE OF TOPICS

Box 2 shows the seven topics selected for the study. Each cell required considerable time and effort to develop fully, and it became necessary to halt the development of one cell (I4 "facilitating the development of quality assurance, including clinical audit in outpatients services") in order to concentrate on the remaining six.
DEVELOPMENTI OI: INDICATORS

As indicators emerged for each cell it became apparent that they fell naturally into three conceptual types: (a) global indicators, (b) restricted indicators, and (c) specific indicators.

Global indicators extend beyond one cell, in that they are relevant in other rows or columns of the matrix. With the audit topic "Input into managerial decision making in health promotion" as an example, an indicator such as:

"Is there a designated public health physician with responsibility for public health medicine input?"

represents a global concept. It would be appropriate to determine the éxistence of a departmental representative in auditing any responsibility of public health medicine in relation to any service category.

Restricted indicators may apply within other cells, but their relevance is limited or "restricted" to one row (responsibility of public health medicine) or one column (service category) of the matrix. They are not universally or globally applicable. Again, with the previous audit topic as an example, an indicator such as:

"Is there a forum within the health board for the development and coordination of health promotion policy, which includes department of public health medicine and health promotion or education representatives?"

is a restricted concept. It does not apply throughout the matrix but would be common to the audit of any public health function in relation to health promotion. Similarly, a developmental or coordinating forum might be required for public health medicine to fulfil its input into the managerial decision making responsibility for service categories other than health promotion.

Specific indicators are relevant to only one cell, applying solely to one responsibility with respect to one service category. With an example from the audit topic "lead responsibility for the development and/or running of screening services," an indicator such as:

"Has a time period been determined within

which all screen positive patients are to be followed up?"

refers specifically to the target setting, planning, and monitoring function of the specialty in relation to screening programmes.

A cell, therefore, can be graphically represented as a model comprising three core types of quality indicator: global, restricted, and specific (figure). Although these subdivisions have not been formally included in the full questionnaires, this model has proved useful in introducing physicians to the concept of the project as a whole, in acting as a focus for the brainstorming approach, and in clarifying where and how a given indicator might fit into a complete cell.

INDFCATOR QLESTIONNAIRE CONCEPT

In developing the indicators several practical problems had to be overcome. Some questions 


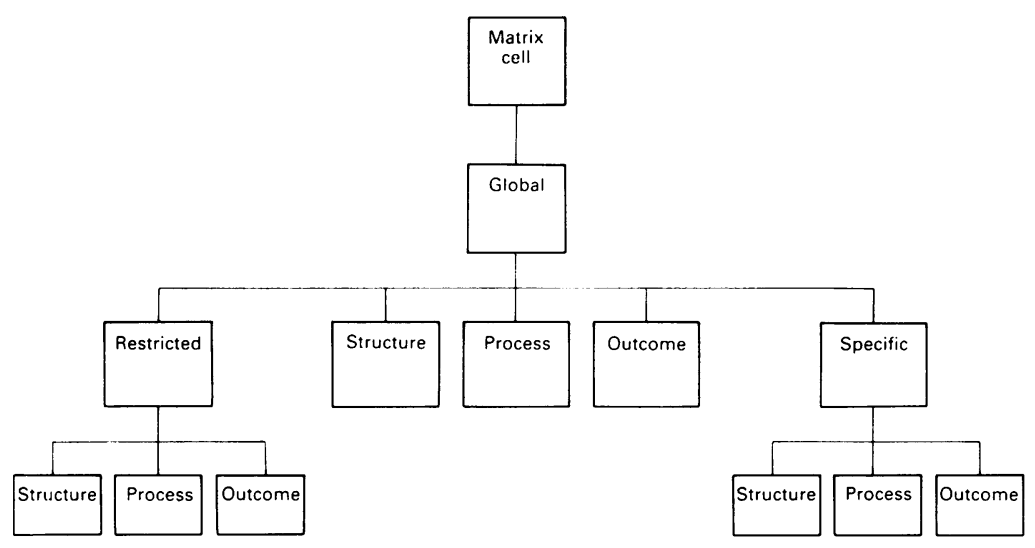

Conceptual cell model ("lead responsibility for the development and/

and responses which were suggested had to extensively adapted or even omitted, for various reasons. Some questions were seen as impractical, being either too specific to certain programmes or so fundamental as not to need inclusion. Others were difficult or impossible to quantify; for example, an indicator examining the "proportion of people contacted in the policy pathway or route" proved difficult to measure, with practice being too variable to allow useful interdepartmental comparison. More generally, any ambiguity or overlap of questions and responses had to be eliminated. The piloting phase contributed significantly to this process of refinement.

In its final form each questionnaire represents a protocol for the audit of a specific part of public health medicine, corresponding to the appropriate cell of the matrix. These protocols aim at facilitating the evaluation of practice in the context of a quality rated questionnaire where a score may be derived and quality measured. In completing the questionnaire a public health department is provided with an objective and quantified audit of its practice, measured against a standard set by consensus.

The questionnaire for each cell comprises structure, process, and outcome sections, each with several questions designed to assess and measure the quality of practice. The questions, or indicators, are all of the "closed" type, calling for responses which are strictly limited. Within this closed typology there are two forms of question: simple alternative question and multiple choice questions.

Each response carries a score, such that those responses which reflect the highest quality provide the highest score. Responses therefore may represent a scale of quality from high scoring (good quality) to low scoring (poorer quality) or may be complementary, where the maximum score may only be derived if all responses are selected.

\section{EXAMPLE OF A QUALITY RATING INDEX} QUESTIONNAIRE

Focusing on the indicators derived for one cell, we describe principles and problems that are representative of all the cells. Reproducing the full questionnaire is not practicable; box 3 gives examples of structure, process, and outcome questions selected from cell D6 or running of screening services."

Box 4 shows abbreviated questions and scores for the entire questionnaire. As with the full questionnaire, these are divided into structure, process, and outcome sections. Although the first seven questions (box 4) relate to the resources available to the department of public health medicine with regard to screening services generally, the remaining questions can be answered meaningfully only with reference to one specific screening programme selected by the department (for example, breast, cervical, or prenatal screening). The scores reflect the relative importance of each question as a means of measuring quality within the departmental screening role.

\section{Discussion}

We have shown that it is possible to develop indicators for public health medicine and to derive a quality rating index for practice within this specialty. Aspects of the weighted score system are unique in the specialty, and therefore certain elements of the method merit further consideration.

\section{Structure}

2 When writing a screening review, or making a case for the development of a service, which of the following resources are available? (Tick all that apply)

Clerical/secretarial support within the Department of Public Health

Access to at least two of the following:

Word processor

Database

Spreadsheet

Graphics package

Laser printer

Statistical specialist within the $\square 1.5$ Department of Public Health

Statistical specialist outwith the $\square 0.5$ Department of Public Health

Process

5 By what means is/was patient feedback sought? (Tick one only)

Systematically from patients $\square$ 。

Systematically by proxy

through health professionals

Unsystematically (for example, $\square_{3}$ poster or leaflets in clinics)

Feedback not sought

Outcome

1 Have $100 \%$ of screened positives been (22) followed up within the predetermined time period: (Tick one only)

Yes

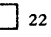

No

Not appropriate (for example, $\square$ N/A time period not yet passed)

Box 3 Selected indicator questions for one cell (D6) 
Nature of question

Structure

1 Topics to be considered in a screening review

2 Resources available for producing review

3 Pathway for the screening policy process

4 Public health physician responsible for screening

5 Secretarial support for designated physician

6 Resources available for literature search

7 Accessibility of the identified literature

The following relate to a specified screening programme

8 Target population specification

9 Plan for monitoring positives

10 Plan for monitoring interval cases

11 Plan for monitoring non-responders

12 Plan for contacting target group

13 Screening targets set

14 Plan for action on unmet targets

15 Time frame for follow up of positives

16 "Acceptable" level of interval cases set

\section{Process}

The following relate to the screening programme specified

1 Are/were screening targets monitored?

2 Are/were screening targets met?

3 Is/was the incidence of interval cases monitored?

4 Methods employed in contacting target population

5 Means of seeking screened patient feedback

6 Is/was mortality monitored?

7 Is/was morbidity monitored?

$8 \mathrm{Is} /$ was incidence monitored (prenatal only)

9 Were screening programme recommendations made?

10 Screening experience shared between boards?

11 Screening programme copes with throughput?

12 Can screening programme be readily modified?

13 Were adverse effects of screening considered?

14 Literature reviewed before recommendations?

15 Time deadline for recommendations met?

16 Did recommendations follow policy pathway?

17 Were economic appraisals undertaken in review?

18 Was statistician consulted in review?

19 Quality of presentation of recommendations?

\section{Outcome}

The following relate to the screening programme specified

$1100 \%$ of positives followed up in time frame?

2 Public health recommendations implemented?

3 Percentage of target population contacted

4 Percentage of eligible target population contacted

5 Public health recommendations accepted by board?

6 Interval cases below "acceptable" level?

Box 4 Abbreviated questions and scores for entire questionnaire on one cell (D6)

SCORING

The Delphi approach used in ascribing scores to the questions and answers in the indicator sets allowed consensus without confrontation, ensuring that every physician had equal opportunity to make a contribution.

The aim of scoring the questions and responses was to find a system which, through the audit method described, could improve public health practice. By using the indicator questionnaire in a departmental audit it is possible to arrive at an index figure for quality of public health medicine between 0 and 100 for the structure, process, and outcome indicators - essentially, a percentage measure of practice quality for that specific dimension of public health medicine activity. The derived score can be compared either with the maximum score obtainable or with the scores obtained by other health boards for the same questionnaire. Thus the quality rating index can be used as a first step in adopting the Standing Medical Advisory Committee's recommendation of comparative quality assessment of the specialty across Britain. ${ }^{9}$

The $0-100 \%$ quality rating index represents an attempt to quantify the quality of practice. Although 0 represents the lowest quality and 100 the highest, it is not a ratio scale - that is, an audit score of $80 \%$ does not necessarily mean that practice is twice as good as activity with an audit score of $40 \%$. The value of the quality rating index lies in closely examining each indicator and relating its importance or weighting to the overall audited score, identifying areas of strength and weakness. The index should be used to prompt and direct a discussion of strategies on where and how to alter practice. Repeating the audit allows the effects of changes in practice to be measured.

\section{GENERALISABILITY}

To ensure that the audit questionnaires produced were valid, generalisable, and quantifiable pilot testing was necessary. During the pilot phase of the study each indicator questionnaire was used by a department other than that which had developed the questionnaire, as a basis for audit of the appropriate area of public health medicine activity. These piloting .meetings were attended by the researchers to observe the audit in practice, assess the questionnaires and instructions, and refine them as appropriate.

A more formal evaluation exercise is currently being undertaken on behalf of the Faculty of Public Health Medicine by the Scottish Affairs Committee. This exercise aims at assessing further the reaction to this approach to audit across all the Scottish health boards and at acting as a clearing house and dissemination vehicle for existing and prospective work in audit questionnaires.

QUALITY IN PUBLIC HEALTH MEDICINE

The issue of quality in public health medicine presents unique problems, requring a radical appraisal of the tools used to measure and improve quality in the diverse parts of the specialty's activity. The matrix developed provides an effective, flexible, and comprehensive framework through which quality can be assessed and improved strategically.

Audit indicators should be generalisable, quantifiable, and routinely measurable. ${ }^{9}$ The cell method, in which specific areas of activity can be pinpointed within the matrix and then defined and critically examined, enables participants to develop for themselves indicators of good quality medical care. By drawing on the contribution of as many physicians as possible the process of developing quality indicators engenders a true 
sense of ownership and acceptance. This is especially important when experience clearly shows that audit or quality assurance activity will work only when it is voluntary. ${ }^{10} 11$

A MODEL FOR QUALITY ASSURANCE

This project provides a comprehensive framework for the quantifiable evaluation of quality. It does not seek to prescribe minimum standards for the practice of public health medicine but to encourage appraisal of current practice, identifying areas where change can be implemented. Subsequent quality ratings with the same indicators provide a means of measuring the effects of changes on the quality of practice.

The matrix and indicator approach to quality assurance allows physicians to complete the "audit cycle" of setting standards, observing practice and comparing with standards, and implementing change. The quality of public health medicine index can identify areas of relative strength and weakness, with clear implications for redirecting effort and resources, thereby improving health care. The principles employed in this approach to quality assurance offer a flexible and systematic method of audit planning and evaluation for public health medicine.

The continuing study aims at evaluating the implementation of these techniques across
Scotland and exploring the extent to which this approach to audit may be adapted and applied to other areas of health care.

We thank all those public health physicians who took part in the initial survey and in developing the matrix, cells, and indicators, and the Grampian Public Health Medicine Audit Committee for its continued support and advice. This project is funded by the Clinical Resource and Audit Group. Full sets of the indicators are available from DAR.

1 Home and Health Department, Scottish Office. Working for patients. Medical audit - Scottish working paper 2 patients. Medical audit
Edinburgh: HMSO, 1989.

2 Faculty of Public Health Medicine. Report of a working group on audit of public health medicine. London: FPHM, 1989

3 Koch H. Obstacles to total quality in health care International fournal of Health Care Quality Assurance 1991;4:30-1

4 University of Edinburgh Research Unit in Health and Behavioural Change. Changing the public health. Chichester: Wiley, 1989.

5 Committee of Inquiry into the Future Development of the Public Health Function. Public health in England. London: HMSO, 1988. (Cmnd 2819.)

6 Donabedian A. Explorations in quality assessment and monitoring. Vols I, II. Ann Arbor, Michigan: Health Administration Press, 1980, 1982.

7 Nuffield Institute for Health Services Studies, University of Leeds. Audit guidelines in public health medicine: an introduction. Mersey Regional Health Authority: Audit in Public Health Medicine Project, 1992.

8 Oppenheim NA. Questionnaire design and attitude measurement. London: Heinemann, 1966.

9 Standing Medical Advisory Committee. The quality of medical care. London: HMSO, 1990.

10 Robson M. Quality circles in action. Aldershot: Gower, 1984.

11 Shaw C. Medical audit - A hospital handbook. London King's Fund Centre, 1989. 